\title{
Trajetórias escolares e prática profissional de docentes das camadas populares
}

\author{
LUCÍOLA LICÍNIO DE CASTRO PAIXÃO \\ SANTOS \\ Universidade Federal de Minas Gerais \\ REGINA LÚCIA CERQUEIRA DIAS \\ Universidade Federal Fluminense
}

Tem sido objeto de pesquisa no campo educacional o sucesso escolar dos alunos oriundos das camadas populares. Os estudos nessa área, tanto internacional (Lahire, 1997; Laurens, 1992) como nacionalmente (Portes, 2003; Viana, 2007; Zago, 2000), buscam identificar fatores que explicariam a longevidade escolar desses estudantes. Dentro dessa perspectiva, este artigo pretende, inicialmente, identificar e analisar alguns fatores que contribuíram para que professoras oriundas das classes populares obtivessem longevidade escolar. Objetiva também compreender as repercussões da formação em nível superior desses sujeitos em suas práticas pessoais e profissionais. Busca, ainda, contribuir para uma reflexão sobre as atuais políticas de formação inicial de professores em nível superior.

O interesse em investigar tais questões adveio da atuação como professora do curso normal superior, que formava docentes para ministrarem aulas na educação infantil e nas primeiras séries do ensino fundamental, em um Instituto Superior de Educação ${ }^{1}$ pertencente a uma fundação, localizado na região metropolitana de

1 No segundo semestre de 2006, o curso normal superior foi extinto na referida instituição e iniciou-se o curso de pedagogia com uma duração menor, de três anos. Em julho de 2009, esse Instituto Superior de Educação foi incorporado pelo Estado. 
Belo Horizonte. O referido instituto era mantido com ajuda do Estado e com seus próprios recursos. Em virtude dessa situação, o instituto podia cobrar mensalidades bem inferiores às das outras instituições de ensino particular, atraindo alunos pertencentes às camadas populares, vindos de cidades próximas a Belo Horizonte, da região metropolitana e mesmo da capital, os quais passavam a ter também a chance de cursar o ensino superior. A fundação remunerava seus professores melhor que várias faculdades situadas na capital e em sua região metropolitana, o que atraía profissionais com uma boa formação acadêmica, sendo a maioria do seu corpo docente composta por mestres e doutores.

Foi observado na atuação docente e de orientação de memoriais acadêmicos do mencionado curso, exigidos como uma das modalidades de trabalho final, que os itinerários escolares das alunas foram, de maneira geral, extremamente acidentados e que houve uma mobilização intensa por parte delas e de seus familiares para que obtivessem longevidade escolar, uma vez que a maioria é proveniente das camadas populares. Outro fato que despertava a atenção dos docentes, originado tanto das leituras dos memoriais como da vivência no curso normal superior, foi a mudança visível e gradativa operada em grande parte das alunas ao longo dos períodos cursados, em aspectos como: maneira de pensar, valores, gostos, uso da língua, e mesmo na maneira de vestir-se e de comportar-se. Além disso, grande parte das alunas-professoras relatava uma substancial mudança ocorrida em suas práticas docentes, a partir do ingresso nesse curso superior.

Em virtude dessas experiências, foi definido o objeto deste estudo e realizada uma pesquisa em que se procurou analisar a trajetória escolar, pessoal, acadêmica e profissional vivida por um grupo de quatro alunas egressas do curso normal superior, com o objetivo principal de investigar as repercussões da formação em nível superior em suas práticas pessoais e profissionais. Todas as participantes do estudo já exerciam a profissão docente ${ }^{2}$ no período anterior ao ingresso na graduação e continuaram a lecionar durante o curso.

Considerando as características específicas do objeto de estudo, optou-se por realizar uma pesquisa qualitativa, utilizando-se a abordagem biográfica. Procurou-se, ao usar tal abordagem metodológica, reconstruir as histórias de vida narradas pelas professoras nas entrevistas, que foram semiestruturadas e em profundidade, ${ }^{3}$ articulando-as ao contexto social vivenciado por elas, pois, de acordo com Fonseca (1999), sem esse movimento interpretativo, as análises de casos particulares pouco acrescentam às pesquisas acadêmicas. Foi considerado também o pertencimento social

2 As participantes do estudo ministram aulas nas séries iniciais do ensino fundamental em escolas públicas municipais e estaduais de Belo Horizonte e, no caso de uma delas, em uma escola de Ibirité, cidade localizada próxima à capital.

3 Com duas das entrevistadas, foram realizadas cinco sessões com cada uma delas, com a duração de uma hora e trinta minutos. Com as duas outras participantes do estudo, foram feitas três sessões com cada uma delas, com a duração de uma hora e trinta minutos, totalizando 24 horas de entrevistas. 
e de gênero dos sujeitos da pesquisa por se acreditar que uma pesquisa sobre docentes que não leva em conta tais pertencimentos acaba por produzir uma visão genérica.

Optou-se por seguir na reconstrução das histórias de vida das professoras uma ordem temporal, da infância até o momento atual vivido por elas. Os estudos sobre formação e prática docente evidenciam a importância dos percursos escolares na construção da identidade profissional e mesmo pessoal dos professores. Para Chaves (2006, p. 165), "na profissão docente a escola é uma instituição onipresente, na qual ingressamos na infância e dela só nos apartamos na aposentadoria”. Em síntese, o que a autora quer dizer é que as instituições escolares e suas práticas nos marcam de maneira profunda, sendo fortes elementos constituintes de identidades. Portanto, além da opção pela ordem temporal na coleta das narrativas do grupo pesquisado, julgou-se fundamental para a investigação reconstruir as trajetórias escolares empreendidas por esses sujeitos. Assim, foram elaboradas várias questões sobre a vida escolar e pessoal, desde a educação infantil até o curso normal superior.

A investigação baseou-se na teoria da ação que sustenta as obras produzidas por Bourdieu e Lahire e pelos estudos desenvolvidos por Perrenoud, sobre a formação e prática docente. Foi utilizado na pesquisa o conceito de habitus, reatualizado por Bourdieu e apropriado e recontextualizado por Perrenoud no campo de formação de professores. No entanto, outros autores que desenvolveram trabalhos sobre a escolarização das camadas populares, formação e prática docente foram também fundamentais para o estudo realizado (Gauthier et al., 1998; Laurens, 1992; Portes, 2003; Tardif, 2002; Viana, 2007; Zago, 2000, entre outros).

Procurou-se no trabalho empreendido, inicialmente, construir um retrato das professoras em relação às suas práticas profissionais e pessoais desenvolvidas ao longo da vida, no período anterior ao ingresso no curso normal superior. Posteriormente, buscou-se compreender e analisar as permanências e mudanças diretas e indiretas proporcionadas por esse curso no âmbito profissional e pessoal.

Duas das professoras pesquisadas têm a mesma idade, 50 anos na época da entrevista, e fazem parte, portanto, de uma mesma geração. As outras duas têm idades também aproximadas, por volta de 30 anos, e, por sua vez, fazem parte de outra geração. Esses dados, somados ao fato de pertencerem originariamente às classes populares, explicam algumas coincidências em relação às trajetórias escolares e profissionais vivenciadas pelas participantes, uma vez que os contextos sociais, o pertencimento social e as políticas educacionais exercem um peso considerável na história de vida dos docentes. Todas as entrevistadas fizeram parte de uma turma do normal superior que concluiu a graduação em 2005.

\section{CONFIGURAÇÕES FAMILIARES E TRAJETÓRIAS ESCOLARES DAS PARTICIPANTES DA PESQUISA}

Inicialmente se buscou retratar a configuração familiar de origem das participantes da investigação. Acerca dessa particularidade, foram feitas aos sujeitos da pesquisa questões sobre a escolaridade dos pais e avós, as interações familiares, 
os hábitos alimentares, o lazer, as práticas religiosas e corporais e a relação das entrevistadas com a leitura e a escrita. Procurou-se ainda investigar a ordem moral doméstica existente nas famílias das entrevistadas. Lahire (1997) apresenta em seu estudo cinco configurações fundamentais para análise da relação família-escola no que se refere aos resultados escolares de crianças provenientes dos meios populares: formas familiares da cultura escrita, as condições e disposições econômicas, a ordem moral doméstica, as formas de autoridade familiar e as formas familiares de investimento pedagógico. A ordem moral doméstica refere-se às noções transmitidas pela família: de bom comportamento, respeito às regras sociais, esforço e perseverança. Esses dados foram fundamentais para a elucidação das maneiras de pensar, sentir e agir das docentes engendradas pelo contexto familiar. Neste artigo, tais configurações serão apresentadas de maneira abreviada.

A família e a escola, responsáveis pelas socializações primária e secundária, são instituições fundamentais na formação dos habitus de um indivíduo. O conceito de habitus, elemento fundamental na teoria da prática desenvolvida por Bourdieu (2006, p. 53-54), é definido pelo autor como:

[...] sistemas de disposições duráveis, estruturas estruturadas predispostas a funcionar como estruturas estruturantes, isto é, como princípio gerador e estruturador das práticas e das representações que podem ser objetivamente "reguladas" e "regulares" sem ser o produto da obediência a regras, objetivamente adaptadas a seu fim, sem supor a intenção consciente dos fins e o domínio expresso das operações necessárias para atingi-los e coletivamente orquestradas, sem ser o produto da ação organizadora de um regente.

Os habitus seriam substancialmente influenciados pela posição dos indivíduos na estrutura social. Dessa forma, os gostos, as crenças, as maneiras de pensar, agir e vestir-se estariam fortemente vinculados à condição social e cultural do indivíduo. Segundo Bourdieu (2008, p. 21), “uma das funções da noção de 'habitus' é a de dar conta da unidade de estilo que vincula as práticas e os bens de um agente singular ou de uma classe de agentes". Os habitus são produtos das divisões existentes no campo social e, ao mesmo tempo, produzem distinções entre os indivíduos e classes, ou seja, "distintos, distinguidos, eles são também operadores de distinções" (idem, p. 22).

As professoras entrevistadas pertencem originalmente às classes populares, tomando-se como referência para situá-las nesse grupo social as dimensões econômica e cultural. Os pais das docentes possuem uma reduzida escolaridade formal, uma vez que nenhum deles prosseguiu os estudos após o antigo curso primário. Economicamente, as profissões a que se dedicaram, como motorista de caminhão, agricultor, pedreiro ou, no caso das mães, servente, babá, não possibilitaram às famílias gozar de tranquilidade financeira. Todas as professoras relataram as inúmeras dificuldades econômicas enfrentadas por elas. O estilo de vida das famílias do grupo de professoras participantes da pesquisa, no que se refere ao lazer e aos gostos culturais, mostrou-se também como típico das classes populares. 
As duas professoras mais velhas nasceram em pequenos povoados da zona rural de Minas Gerais, e suas famílias migraram para Belo Horizonte na década de 1960 em busca de melhores condições de vida e oportunidade de uma maior longevidade escolar para os filhos. Os pais dessas participantes da pesquisa também nasceram e viveram em povoados da zona rural do referido estado e fixaram residência em pequenas cidades próximas à capital mineira, na década de 1980, a fim de que seus filhos pudessem estudar.

Essas professoras, oriundas das classes populares, conseguiram obter uma grande longevidade escolar. A pesquisa apontou vários aspectos comuns em suas histórias de vida que lhes permitiram alcançar tal êxito. Um desses fatores refere-se à atuação importante exercida pelas mães das entrevistadas, ou madrasta e avó no caso de uma delas, que as incentivaram de todas as maneiras possíveis a prosseguirem seus estudos. A ordem moral doméstica existente nas famílias das professoras se constitui em outro elemento de grande importância para a explicação da longevidade escolar que as docentes atingiram. Havia nas famílias das professoras uma regularidade em relação às atividades, horários e regras que, de acordo com Lahire (1997, p. 26), "produzem estruturas cognitivas ordenadas, capazes de pôr ordem, gerir, organizar os pensamentos", ou seja, propiciam uma ordem cognitiva que é esperada pelas escolas primárias. Dessa maneira, essa configuração familiar compensou de certo modo o baixo capital escolar e econômico que os pais das participantes da pesquisa possuíam.

Foram relatadas pelas docentes inúmeras estratégias utilizadas por suas mães, ou madrasta e avó, para superar as dificuldades advindas desses baixos capitais e assim obter êxito na escolarização dos filhos. Para compensar a falta de livros em casa, recorria-se a sebos para adquirir as obras por um preço mais baixo. Mesmo enfrentando a falta de recursos econômicos, seus pais adiavam o ingresso dos filhos no mercado de trabalho a fim de que eles pudessem dedicar-se em tempo integral aos estudos. As mães das entrevistadas procuravam ajudar nas tarefas escolares e, à medida que suas filhas avançavam em relação à escolaridade e elas não mais conseguiam auxiliar no dever de casa, procuravam a ajuda de amigos e vizinhos para essa tarefa. Uma delas relatou que sua mãe não media esforços para que as filhas estudassem. O dinheiro que recebia como costureira, principalmente no final do ano, quando as encomendas de roupas aumentavam, reservava para comprar o material escolar que suas filhas necessitavam. Ia a uma loja no centro de Belo Horizonte e comprava livros didáticos usados e cadernos com algum tipo de defeito que tinham um preço menor.

As estratégias das famílias em busca do sucesso escolar para suas filhas, evidenciadas pela pesquisa, coincidem, em vários aspectos, com as descobertas de estudos sobre a longevidade escolar de indivíduos oriundos das classes populares como, por exemplo, os de Lahire (idem), Portes (2003), Viana (2007) e Zago (2000). Graças à mobilização dessas famílias, as professoras participantes da pesquisa cursaram o ensino superior, mesmo que tardiamente, como no caso das duas participantes mais velhas. Todavia, é preciso salientar que houve um grande esforço pessoal das 
professoras que deve ser também considerado para a compreensão da longevidade escolar que obtiveram. Elas e suas famílias sacrificaram-se, abstendo-se de muitos prazeres, a fim de investirem na escolarização.

Uma das entrevistadas mais velhas, doravante B, relatou que após o curso primário passou a estudar em uma escola particular, pois sua família conseguiu uma bolsa de estudos que cobria parte da mensalidade. Segundo a entrevistada, a instituição privada não tinha biblioteca, o espaço físico do estabelecimento de ensino era exíguo e não proporcionava vivências culturais de qualidade.

No entanto, em meados da década de 1970, Belo Horizonte dispunha de algumas escolas públicas de qualidade, como o Colégio Estadual Central, o Colégio Municipal e o Instituto de Educação. Se estudava em uma escola particular no centro da cidade, não poderia ter deixado de saber que o Instituto de Educação era uma escola gratuita. As duas instituições são relativamente próximas. A grande questão é que essa escola talvez estivesse fora dos horizontes de sua família, pois os alunos que nela ingressavam eram submetidos a um exame de seleção. Só entravam nas escolas públicas que ofereciam o antigo curso ginasial alunos de bom desempenho acadêmico, o que não devia ser o caso da entrevistada. Assim, fica difícil dizer se realmente faltavam informações à família ou se a escolha do estabelecimento de ensino foi determinada pela visualização de sua família sobre suas possibilidades de êxito.

O início da vida escolar na cidade grande foi, na narrativa de B, decepcionante. Em seu relato, afirmou que, como seu rendimento escolar era muito fraco, no término do ano letivo sua professora aconselhou sua mãe a tirá-la da escola, pois considerava que ela não estava preparada para a vida estudantil.

Bourdieu (2003) afirma que o capital cultural sempre retorna às mãos do capital cultural, pois os bens simbólicos só podem ser apreendidos e possuídos por aqueles indivíduos que possuem o código, o qual permita entendê-los. A entrada franca a uma exposição de pinturas por si só não garante o real acesso das classes populares a esse tipo de arte, visto que esse segmento não possui as referências necessárias para a fruição desse gênero artístico. Em relação à escola, algo semelhante ocorre, pois permitir apenas o acesso dos alunos das camadas desfavorecidas à escola não garante a eles uma verdadeira aprendizagem, uma vez que há, segundo o autor, uma enorme distância entre a cultura veiculada nas instituições de ensino e a cultura dessas camadas sociais. Na época retratada por B, década de 1960, o acesso às escolas começava a ser estendido, mas isso não significava, e ainda não significa nos dias atuais, a permanência desses alunos nessas instituições. De acordo com o autor:

Pela prática de uma pedagogia implícita que exige a familiaridade prévia com a cultura dominante e que procede pela técnica de familiarização insensível, um sistema de ensino propõe um tipo de informação e de formação acessíveis exclusivamente àqueles sujeitos dotados do sistema de disposições que constitui a condição de êxito da transmissão e da inculcação da cultura. Eximindo-se de oferecer a todos implicitamente, quer exigir de todos uniformemente que 
tenham o que não lhes foi dado, a saber, sobretudo a competência linguística e cultural e a relação de intimidade com a cultura e com a linguagem, instrumentos que somente a educação familiar pode produzir quando transmite a cultura dominante. (idem, p. 307)

A participante B destacou sua experiência em uma escola particular em que obteve uma bolsa de estudos. De acordo com seu depoimento, essa instituição era frequentada por alunas pertencentes às camadas média e alta. Durante um ano, ela estudou nesse estabelecimento de ensino e esteve imersa em um mundo totalmente diferente de tudo que conhecera até então. Os hábitos dos docentes e suas metodologias de ensino e a aparência das colegas foram relatados pela entrevistada, que possivelmente percebera, nesse momento, de maneira mais intensa, uma grande desigualdade social e cultural.

O curso tinha duração de um ano, em regime de semi-internato. Na parte da manhã ia para a sala de aula, à tarde para as oficinas de arte. No início, tinha a impressão de estar vivendo em outro mundo. Os professores tinham outros hábitos e uma maneira bem diferente de ensinar, muitos não explicavam a matéria mais de uma vez, e se a gente não aprendia, o azar era nosso. As colegas de classe eram bem diferentes de mim, começando pela aparência: pele boa, cabelos bem tratados, roupas e sapatos caros. Frequentavam um programa na TV Itacolomi, algumas até desfilavam. Na sala de aula, essa diferença era bem evidenciada. Formávamos dois grupos: as alunas internas e as outras do horário escolar. Por vir de uma escola pobre, eu tinha dificuldade para entender alguns conteúdos transmitidos. Apesar de estudar muito, nunca consegui alcançar o desempenho que as outras alunas apresentavam.

Ela relatou ainda que, apesar do desconforto sentido nessa instituição, "foi uma época de grandes aprendizagens, tanto acadêmicas quanto culturais", constituindo-se em uma "ponte que transformou a menina rural na adolescente que aos poucos se tornou urbana".

Após o curso de admissão, ela conseguiu passar em um teste de seleção para ingresso em uma escola municipal, recém-construída, para cursar a segunda fase do ensino fundamental. A docente $B$ revelou que se sentiu extremamente feliz por ter sido aprovada nesse estabelecimento de ensino e por ser aluna de uma instituição cujas estruturas física e pedagógica eram excelentes. Também evocou as boas experiências e lembrou-se de professores que a marcaram positivamente. A entrevistada relatou que fez o ensino médio em escolas pedagogicamente muito fracas, no período noturno. De acordo com a docente, a empresa na qual passou a trabalhar the remunerava muito bem na época, então, os estudos foram relegados a um segundo plano. Para B, o trabalho sempre ocupou um lugar primordial em sua vida, pois the permitia assistir financeiramente sua família, que tanto necessitava de sua ajuda.

As duas entrevistadas, cuja idade estava em torno de 30 anos, na ocasião das entrevistas, serão denominadas de $\mathrm{C}$ e D. Essas duas professoras mais novas 
são oriundas de famílias menores, em relação às famílias das duas mais velhas. A primeira delas, a entrevistada $\mathrm{C}$, relatou que iniciou seus estudos aos 6 anos de idade. Cursou o antigo pré-primário em uma escola que só contava com essa série. Antes de ingressar no pré-primário, sua família residia na zona rural, mas, como lá só havia estabelecimentos de ensino que atendiam até o último ano do primário, seus pais decidiram se mudar para que suas filhas continuassem a estudar.

Sobre as práticas de leitura e escrita escolares, $\mathrm{C}$ falou que teve seus contatos iniciais na primeira série do ensino primário, o que na época era normal nas escolas públicas. Ela recorda-se que, após o término do pré-primário, sua família foi obrigada a procurar outro estabelecimento de estudo para continuar sua escolarização. Dessa maneira, ingressou em uma escola estadual próxima à sua casa que tinha um bom ensino e era muito procurada pelos estudantes da região, permanecendo nessa instituição até concluir o curso de magistério (em nível médio).

Apesar de não ter tido problemas para se adaptar a essa nova escola e de gostar de sua professora da primeira série do primário, $\mathrm{C}$ afirmou que não conseguiu aprovação por não ter aprendido a ler e a escrever. Aponta ser o motivo de suas dificuldades nessa série o fato de ter sido uma criança raquítica, pequena, imatura para tais aprendizagens. Ela ainda relatou que no ano seguinte foi aprovada e teve uma professora que lhe deixou muitas marcas positivas, tanto que estabeleceu com ela uma relação de amizade que dura até a atualidade. A participante $\mathrm{C}$ nunca mais foi reprovada $\mathrm{e}$ afirmou que era uma estudante muito esforçada, responsável, apesar de não se destacar nos estudos. Disse que sempre foi uma aluna mediana, mas que tinha pavor de tirar uma nota abaixo da média; nas poucas vezes em que isso acontecia, ficava arrasada e chorava muito. Bastante tímida, quase não participava das aulas.

Em suas entrevistas, $\mathrm{C}$ mostra que seus pais possuíam poucos recursos econômicos para investirem em práticas culturais e de lazer, e assim reproduziam seu estilo de vida na formação educacional de suas filhas. Como a escola também não ofereceu tais práticas, C só foi conhecer um teatro e um cinema quando já cursava o ensino superior.

$\mathrm{O}$ relato de $\mathrm{C}$ sobre essa etapa de sua escolarização evidencia sua boa relação com a escola e sua adequação ao mundo escolar, apesar da repetência na primeira série do ensino fundamental. A ordem moral doméstica existente em sua casa foi interiorizada pela entrevistada e moldou seu perfil de estudante, que se caracterizava pelo esforço, disciplina, obediência às regras escolares, o que, a despeito do fraco capital cultural e escolar de seus pais, favoreceu sua integração à escola, pelo fato de esses traços, de acordo com Lahire (1997), estarem próximos ao esperado dos estudantes pelas escolas.

$\mathrm{Na}$ entrevista com $\mathrm{D}$, ela diz recordar-se que suas primeiras experiências escolares se deram quando sua mãe a matriculou em uma escola de educação infantil, próxima à sua casa, quando ela tinha 6 anos de idade. No entanto, ela recusou-se veementemente a estudar nessa idade e sua mãe acabou por fazer a sua vontade. Lembra-se ainda que tinha vontade de aprender a ler, mas não por intermédio da escola. Sua mãe comprava-lhe vários livros infantis e os lia para ela e procurava 
ensinar-lhe a ler e a escrever. Porém, a convivência com duas amigas mais velhas que já frequentavam a escola fez com que $\mathrm{D}$ começasse a decodificar as primeiras palavras e "foi assim, brincando de escolinha com elas", que aprendeu a ler.

Dessa maneira, segundo ela, quando aos 7 anos ingressou na escola, já estava alfabetizada. Nessa idade, já tinha superado o medo da escola e fazia questão de ir sozinha, sem a sua mãe. Possivelmente, D sentiu-se tranquila nesse momento de sua vida para ingressar na escola em virtude de já ter aprendido a ler e a escrever.

$\mathrm{O}$ relato de $\mathrm{D}$ sobre sua escolarização em escolas públicas, até o ingresso no curso superior, mostra que sua trajetória escolar foi marcada pelo bom desempenho. Ingressou na escola já adiantada quanto à aprendizagem da leitura e da escrita em relação às outras crianças. Teve uma professora, logo no início de sua vida escolar, que, segundo ela, tinha uma ótima relação com os alunos e uma boa prática docente. A entrevistada parece ter interiorizado um sentimento positivo por ter tido sua capacidade de aprender reconhecida pela escola e essa confiança em sua capacidade de aprender acompanhou-a durante a sua escolarização.

De acordo com D, a mesma só foi conhecer cinema e teatro depois de casada. Confessou que tinha muita vergonha por nunca ter ido a esses lugares e escondia esse fato de suas colegas, no curso de magistério, quando elas faziam comentários sobre filmes ou peças teatrais. Percebe-se pelos relatos de D como as escolas que frequentou não foram capazes de oferecer práticas culturais significativas, experiências essas que seus pais não puderam proporcionar a ela.

Nos relatos das duas entrevistadas mais velhas evidenciam-se as marcas negativas que alguns professores e práticas excludentes ministradas pelas escolas em que estudaram imprimiram sobre elas. Mas, de acordo com Lahire (2006), um indivíduo, durante sua vida, estabelece diversas relações que podem sedimentar ainda mais suas disposições formadas na infância ou contribuir para que se criem novas disposições. Portanto, essas professoras, felizmente, também tiveram encontros com outros docentes e contatos com práticas escolares que exerceram uma influência positiva sobre elas, amenizando o sentimento de que não eram capazes de aprender ou, pelo menos, evitando que interrompessem seus estudos. A docente $\mathrm{C}$ teve uma trajetória escolar relativamente tranquila, marcada por um grande esforço pessoal. No entanto, é preciso assinalar que $\mathrm{D}$ se diferencia das outras entrevistadas por ter tido uma trajetória escolar marcada pelo sucesso e por não ter se deixado abalar em nenhum momento pelos aspectos negativos que vivenciou como aluna ao longo de sua escolarização.

\section{MUDANÇAS E PERMANÊNCIAS NAS PRÁTICAS PESSOAIS E PROFISSIONAIS DAS PARTICIPANTES DA PESQUISA OCASIONADAS PELA FORMAÇÃO NO CURSO NORMAL SUPERIOR}

Com a análise dos relatos de vida das quatro entrevistadas, foi possível inferir que a opção que fizeram pelo exercício do magistério está relacionada, por um lado, às experiências positivas com bons professores que ministravam aulas interessantes e motivadoras e possuíam uma boa relação com os seus alunos. Por outro lado, 
percebe-se que essa escolha profissional foi também motivada por questões ligadas aos seus pertencimentos de classe e gênero. Bourdieu (2008) chama a atenção para o fato de que desenvolvemos ao longo da vida um sentido de jogo, que nos facilita tomar decisões e sonhar com o possível. Isso significa que, ao agirmos cotidianamente, como em um jogo, não precisamos parar a todo momento, antes de cada ato, e examiná-lo para então escolhermos as nossas ações. O habitus é, portanto, de acordo com o autor, "essa espécie de senso prático do que se deve fazer em dada situação - o que chamamos, no esporte, o senso de jogo, arte de antecipar o futuro do jogo inscrito, em esboço, no estado atual do jogo" (idem, p. 42).

O fato de as professoras, sujeitos desta pesquisa, enfrentarem em sua vida inúmeras dificuldades econômicas as levou a se decidirem pelo curso de magistério, pois essa formação possibilitaria que adquirissem uma profissão precocemente, o que facilitaria a inserção no mercado de trabalho. Constata-se, dessa forma, que o senso de jogo, explicitado por Bourdieu, foi posto em ação por essas docentes no momento da escolha profissional.

Por ser o magistério uma profissão tradicionalmente reservada às mulheres, especialmente o seu exercício nas primeiras séries escolares, percebe-se que tal fato também exerceu um peso considerável na decisão tomada por elas relativa à sua profissão. Houve também, em relação a três delas, o desejo de seus familiares de que se tornassem professoras, o que as influenciou a se decidirem por tal caminho profissional.

As participantes da pesquisa relataram que, ao ingressarem no curso normal superior, tiveram dificuldade para entender a linguagem de alguns professores, pois estes docentes possuíam um vocabulário muito acima da compreensão dos alunos. Em relação a essa dificuldade exposta por elas, Bourdieu e Passeron (1975) tecem várias considerações. Segundo os autores, de todos os elementos que compõem uma situação de aprendizagem, a linguagem do professor se constitui no mais importante de todos eles. Assim, para o sucesso ou o fracasso dos alunos, quanto mais distante o indivíduo estiver em relação à linguagem acadêmica, o que ocorre com uma frequência muito grande com aqueles oriundos das classes populares, mais chance de fracassar nos estudos ele terá.

Os autores ironizam a linguagem distanciada dos professores em relação aos alunos e mostram como essa distância, inclusive, faz parte das estratégias utilizadas por esses profissionais para marcarem uma posição hierárquica superior, o que ele chama de "farda do discurso". Para Bourdieu e Passeron (idem, p. 123): "O professor tradicional pode abandonar o arminho e a toga, e ele pode mesmo gostar de descer de seu estrado a fim de misturar-se à multidão, mas não pode abdicar de sua proteção última, o uso professoral de uma língua professoral". $O$ fato é que a linguagem professoral, para os autores, faz parte da ação pedagógica de inculcação da cultura legítima e, ao mesmo tempo, da "autoridade pedagógica da comunicação e do conteúdo comunicado".

As entrevistadas relataram que também tiveram muita dificuldade em entender os textos dados pelos professores para leitura. Somente com o passar 
do tempo foram se adaptando à linguagem de alguns docentes e compreendendo melhor esses materiais.

A análise de Perrenoud sobre o habitus profissional dos professores foi fundamental para a pesquisa. $\mathrm{O}$ autor apropria-se e recontextualiza o conceito de habitus utilizado por Bourdieu no campo de formação de professores. Para Perrenoud (1993, p. 108), o habitus "é formado por rotinas, por hábitos no sentido comum da palavra, mas também por esquemas operatórios de alto nível”. O autor advoga que o trabalho do professor em seu cotidiano é repleto de situações novas e imprevistas, e para dar conta delas o docente é obrigado a improvisar respostas, mas esse ato não é simplesmente uma repetição mecânica, pois ele obriga o professor a inovar. Quanto à prática docente, os relatos feitos pelo grupo de professoras mostraram mudanças importantes no habitus profissional, provocadas pela formação no curso normal superior. De acordo com as docentes, suas maneiras de preparar, conduzir suas aulas e corrigir as atividades realizadas por seus alunos modificaram-se bastante. Disseram também conseguir ir além dos livros didáticos em suas aulas e utilizar outros materiais interessantes e apropriados ao entendimento dos estudantes. $\mathrm{O}$ conhecimento prévio que seus alunos possuíam passou a ser levado em consideração por elas, e os erros cometidos em provas e atividades passaram a ser analisados de forma mais cuidadosa, servindo de diagnóstico da situação em relação ao nível de aprendizagem em que se encontravam.

Transformações na dimensão afetivo-relacional também foram um fator ressaltado por elas, pois disseram ter se aproximado ainda mais de seus alunos, buscando uma participação efetiva em sala de aula, o que facilitou a gestão da disciplina nas turmas em que lecionavam. Essas transformações narradas pelas docentes parecem evidenciar que a formação adquirida no curso normal superior possibilitou, em parte, a tomada de consciência de que Perrenoud (2001) nos fala, tão importante para a mudança de esquemas postos em prática pelos professores em seu cotidiano profissional. No entanto, acredita-se que suas histórias pessoais, escolares e profissionais também concorram para explicar tais mudanças, pois o conhecimento adquirido no curso superior poderia não ter fortes repercussões sobre suas disposições como professoras. O fato de as docentes exercerem concomitantemente os papéis de alunas e professoras parece ter propiciado a elas uma situação privilegiada para que fizessem uma reflexão sobre sua atividade profissional. As experiências nos estágios, tanto os que foram feitos no magistério em nível médio quanto os que foram realizados no curso normal superior, revelaram-se de maneira geral, em virtude da forma tradicional como foram estruturados, ${ }^{4}$ de pouca valia para a aprendizagem da prática docente.

4 O estágio exigido pelo curso normal superior da referida instituição era realizado pelos alunos nos trề últimos períodos do curso. Cabia ao professor coordenador, responsável pelo estágio, orientar seu aluno na elaboração e execução dessa prática de ensino, mas não havia um efetivo acompanhamento nas escolas em que os estudantes realizavam essa aprendizagem. Existia um tempo para as discussões sobre as impressões e dificuldades 
No entanto, existem práticas pessoais e profissionais que não se modificaram, ou sofreram pequenas alterações. Tais permanências parecem indicar que alguns dos problemas vivenciados pelo grupo de docentes, advindos de suas formações familiar e escolar, ainda não foram superados e repercutem em suas vidas, tanto na dimensão pessoal quanto na profissional.

Não foi possível às participantes da pesquisa, por causa do baixo capital econômico, cultural e escolar de seus pais, frequentarem com assiduidade espaços culturais que as colocassem em contato regular com as diversas manifestações existentes nesse campo, fundamentais para que o professor, entre outras possibilidades, enriqueça o seu repertório de saberes e possa ir além dos conteúdos existentes nos livros didáticos em suas aulas. Os relatos feitos por essas professoras sobre suas trajetórias escolares indicam que tal vazio continuou a existir, uma vez que as instituições de ensino que frequentaram não se preocupavam em proporcionar a seus alunos vivências culturais consideradas legítimas e diferentes daquelas existentes em seu meio social. Para os indivíduos pertencentes às classes média e alta, esse tipo de problema costuma ser solucionado com maior facilidade, pois se as escolas frequentadas por eles falham nessa direção, os pais rapidamente suprem essa deficiência, o mesmo não ocorre com os indivíduos pertencentes às classes populares.

Há, portanto, uma lacuna em relação a esse tipo de experiências culturais na vida das professoras entrevistadas, as quais elas ainda não foram capazes de preencher. Não se percebe um movimento vigoroso por parte dessas docentes para superar esse vazio em suas formações, apenas algumas tímidas tentativas. $\mathrm{O}$ curso normal superior também não representou um divisor de águas em relação a essa lacuna. A disciplina atividades integradas de pesquisa (AIP), ${ }^{5}$ que tinha como objetivo contribuir para a ampliação das experiências culturais das alunas, foi uma importante iniciativa nessa direção, mas sabe-se que para isso era necessário mais que algumas atividades curriculares aos sábados.

Em relação ao capital cultural, a origem dos indivíduos exerce nesse âmbito um peso considerável sobre suas disposições em relação aos estilos de vida que adotam (Bourdieu, 2007). Isso não quer dizer que essas disposições não possam transformar-se, pois os indivíduos estabelecem outras relações ao longo de suas trajetórias pessoais e profissionais. No entanto, nos casos analisados na pesquisa, as professoras ainda não tinham sido capazes de reverter de maneira significativa tais disposições, pelo menos até aquele momento.

Ainda assim, duas das entrevistadas procuravam propiciar a seus alunos novas experiências, levando-os a visitar espaços culturais existentes fora dos muros das

dos alunos, porém, tanto os professores responsáveis pelos estágios como os alunos o julgavam insuficiente.

5 A disciplina denominada AIP compunha o currículo do curso normal superior e era ministrada aos sábados. Eram feitas com as alunas visitas a exposições e museus e assistiam-se a filmes e a espetáculos de teatro e dança. $\mathrm{O}$ objetivo dessa disciplina era permitir às alunas uma maior inserção cultural, considerada fundamental para a formação docente. 
escolas em que lecionavam. Outra entrevistada não proporcionava aos seus alunos, também pertencentes às classes populares como ela, essa inserção em atividades culturais produzidas fora do espaço escolar, reproduzindo, como professora, mesmo que de maneira inconsciente, seu processo de formação. Alegava não proporcionar aos estudantes saídas para a fruição de produções culturais por causa das dificuldades econômicas de seus alunos, muitos não possuíam recursos necessários para arcar com essas atividades, e também pela falta de incentivo da Secretaria de Educação. Contudo, esses tipos de problemas não são incontornáveis, como bem o demonstraram as outras professoras. A entrevistada que lecionava há muito tempo a disciplina matemática também não mencionou qualquer tipo de passeio com seus alunos a espaços culturais.

No que se refere à participação das entrevistadas em seu sindicato profissional, em movimentos realizados por sua categoria profissional ou em outros movimentos sociais, as narrativas feitas pelo grupo de professoras indicavam que suas disposições anteriores à entrada no curso superior não sofreram alterações. Elas assumiram uma postura de apatia e desinteresse em relação ao sindicato de sua categoria e não participavam de nenhum movimento social, caminhando na contramão da história de muitas mulheres brasileiras que militaram em movimentos feministas, sindicalizaram-se e vinham ocupando, de acordo com Giulani (2009), mesmo que lentamente, os microfones e os cargos de direção nos sindicatos. Não se pode deixar também de registrar que o desinteresse, por grande parte dos professores, pelas lutas e mobilizações lideradas pelos sindicatos está relacionado às inúmeras derrotas sofridas por esses órgãos nos movimentos por aumento salarial.

As entrevistadas alegaram não participar de seus sindicatos pelo fato de encontrarem nesses órgãos os mesmos vícios que observavam na política nacional e de não atuar em nenhum movimento social em virtude da carga exaustiva de trabalho a que estavam submetidas. Apesar da complexidade de que se reveste tal questão, pois para discuti-la seria necessário uma análise do movimento sindical, bem como do enquadramento sociopolítico da categoria docente, é importante considerar as consequências de tal atitude no papel de educadoras que as professoras exercem. Como ajudar a formar alunos críticos e participativos, se o próprio professor se abstém de participar de seu sindicato, ou de qualquer outro movimento social?

Três das entrevistadas relataram, a respeito de suas disposições pessoais, ter ocorrido uma alteração significativa no que tange à dimensão religiosa. Durante os períodos da infância e adolescência, suas famílias, que eram católicas, as educaram dentro dos preceitos dessa religião, levando-as a frequentarem as missas e envolvendo-as na preparação e execução das atividades que existiam na igreja. No entanto, após se afastarem de suas famílias, tal disposição não foi mais reforçada e passaram a não mais se interessar por uma prática religiosa institucionalizada. $\mathrm{O}$ fato de terem avançado na escolarização e, dessa forma, assumirem uma posição mais crítica em relação às instituições religiosas parece ter exercido também sobre elas uma influência importante no que se refere às suas disposições. 
Sobre os estilos de vida adotados no que se refere à alimentação, vestuário, práticas corporais e gosto musical, a formação adquirida no curso superior parece não ter provocado alterações. De acordo com Bourdieu (2007), os habitus produzem os estilos de vida, e, no caso das professoras entrevistadas, eles permaneceram sem alteração em relação às suas preferências nessas dimensões. No entanto, de acordo com as narrativas feitas pelo grupo de professoras, a linguagem - que, segundo o autor, se insere em um dos subespaços simbólicos, cujo conjunto forma os estilos de vida - sofreu uma alteração significativa em relação à escrita. $O$ fato de terem passado a ler mais e enriquecido o vocabulário tornou, segundo elas, suas escritas mais elaboradas; porém, o mesmo não ocorreu em tal intensidade com a linguagem oral.

De acordo com as professoras pesquisadas, a formação propiciada a elas pelo curso normal superior as ajudou a solucionar problemas relativos ao ensino de algumas disciplinas, especialmente português e matemática, o que lhes proporcionou uma maior segurança para lecionar essas disciplinas. As entrevistadas também mencionaram os cursos de formação feitos em outros espaços, que foram importantes para que mudassem para melhor suas práticas docentes. Além disso, disseram que as trocas de experiências que estabeleceram com algumas colegas de trabalho também as ajudaram a enriquecer suas práticas profissionais.

Não se pode deixar de mencionar as difíceis condições de trabalho a que as professoras participantes da pesquisa estão submetidas e a péssima remuneração que recebem ao exercerem um ofício tão importante e exaustivo como é o trabalho do professor. É necessário também ressaltar que todas as docentes continuaram a estudar após a conclusão do curso superior e já concluíram pós-graduações na área educacional em nível lato sensu.

\section{CONSIDERAÇÕES FINAIS}

A pesquisa desenvolvida evidenciou a luta empreendida pelas participantes da pesquisa e suas famílias na busca por uma longevidade escolar. A análise das trajetórias escolares dessas professoras, oriundas das classes populares, ajuda-nos a compreender melhor os inúmeros obstáculos encontrados pelos indivíduos dessas classes durante esse caminho e as estratégias utilizadas na tentativa de vencê-los.

No entanto, ainda que os sujeitos dessa investigação tenham logrado um grande êxito, contrariando os dados de estatísticas educacionais que demonstram que o fracasso escolar atinge ainda hoje maciçamente os indivíduos pertencentes às classes desfavorecidas, é preciso atentar também para os problemas apontados neste texto, advindos de suas trajetórias pessoal, escolar e profissional, que repercutem em suas práticas profissionais. A pesquisa demonstrou que, ainda que o curso normal superior tenha contribuído para um crescimento pessoal e profissional das docentes, não representou uma transformação vigorosa em relação a aspectos importantes para a formação e constituição da identidade de um professor que atue com a qualidade julgada necessária.

A instituição de ensino em que as participantes da pesquisa buscaram aperfeiçoar-se como professoras possuía, ainda que tivesse um corpo docente 
bem qualificado, limites a uma formação de qualidade, dados principalmente pela sua constituição como um instituto superior de educação. A Lei de Diretrizes e Bases da Educação Nacional (LDB) (Brasil, 1996) criou esse tipo de instituição como uma alternativa à formação de docentes nas universidades. Dessa forma, sem grande dispêndio de recursos, os institutos podem formar professores sem se preocupar em conjugar as atividades de ensino à pesquisa e extensão, como ocorre nas universidades. É que para tais institutos não se exige a mesma proporção de professores qualificados (mestres e doutores) determinada para uma universidade. A maioria dos docentes que atua nos institutos recebe pelo número de aulas dadas, poucos possuem dedicação exclusiva, o que os obriga a lecionar em mais de uma instituição.

Os professores da educação básica são oriundos de diversas classes sociais, mas assistimos nos últimos anos a um aumento no número de docentes pertencentes originariamente às classes populares. Daí a importância de compreendermos melhor quem são esses sujeitos, suas trajetórias escolares e pessoais, suas particularidades. Tal compreensão nos ajudará a repensar os cursos de formação docente, sobretudo sua estrutura e prática curriculares. Tal compreensão nos ajudará a refletir sobre a formação em serviço, vislumbrando novas possibilidades de intervenção. Tal compreensão, enfim, nos tornará mais conscientes dos limites e dos desafios no campo da formação e do trabalho docente.

\section{REFERÊNCIAS}

Bourdieu, Pierre. A economia das trocas simbólicas. 5. ed. São Paulo: Perspectiva, 2003. .A sociologia de Pierre Bourdieu. In: Ortiz, Renato (Org.).A sociologia de Pierre Bourdieu. São Paulo: Olho d'Água, 2006.

. A distinção: crítica social do julgamento. São Paulo: EDUSP, 2007.

. Razões práticas: sobre a teoria da ação. 9. ed. Campinas: Papirus, 2008.

.; Passeron, Claude. A reprodução: elementos para uma teoria do sistema de ensino. Rio de Janeiro: Francisco Alves, 1975.

Brasil. Lei n. 9.394, de 20 de dezembro de 1996. Estabelece as diretrizes e bases da educação nacional. Brasília, DF, 1996. Disponível em: <http://portal.mec.gov.br/seed/ arquivos/pdf/tvescola/leis/lein9394.pdf >. Acesso em: set. 2011.

Chaves, Silvia Nogueira. Memória e autobiografia: nos subterrâneos da formação docente. In: SouzA, Elizeu Clementino de. Autobiografias, histórias de vida e formação: pesquisa e ensino. Porto Alegre: EDIPUCRS, 2006. p. 161-176.

Fonseca, Claudia. Quando cada caso NÃo é um caso: pesquisa etnográfica e educação. Revista Brasileira de Educą̧ão, Rio de Janeiro, ANPEd, n. 10, p. 58-78, jan./abr. 1999.

Gauthier, Clemont et al. Por uma teoria da pedagogia: pesquisas contemporâneas sobre o saber docente. Ijuí: Unijuí, 1998. 
Giulani, Paola Capellin. Os movimentos de trabalhadoras e a sociedade brasileira.In: Priore, Mary del (Org.); Bassanezi, Carla (Coord. de Textos). História das mulheres no Brasil. São Paulo: Contexto, 2009. p. 640-667.

LAhire, Bernard. Sucesso escolar em meios populares: as razões do improvável. São Paulo: Ática, 1997. 2006.

. Retratos sociológicos: disposições e variações individuais. Porto Alegre: Artmed,

Laurens, Jean-Paul. I sur 500: la reussite scolaire em milieu populaire. Toulouse: Presses Universitaires du Mirail, 1992.

Perrenoud, Philippe. Práticas pedagógicas, profissão docente e formação: perspectivas sociológicas. Lisboa: Dom Quixote, 1993.

. O trabalho sobre o habitus na formação de professores: análise das práticas e tomada de consciência. In: PaQuay, Léopold et al. (Orgs.). Formando professores profissionais: quais estratégias? Quais competências? 2. ed. Porto Alegre: Artmed, 2001. p. 161-184.

Portes, Ecio Antonio. Trajetórias escolares e vida acadêmica do estudante pobre da UFMG. Tese (Doutorado) - Universidade Federal de Minas Gerais, Belo Horizonte, 2003.

TARdif, Maurice. Saberes docentes e formação profissional. Petrópolis: Vozes, 2002.

VIAnA, Maria José Braga. Longevidade escolar em famílias populares: algumas condições de possibilidade. Goiânia: Editora UCG, 2007.

ZAGo, Nadir. Quando os dados contrariam as previsões estatísticas: os casos de êxito escolar nas camadas socialmente desfavorecidas. Paidéia, Ribeirão Preto, FFCLRP-USP, v. 10, n. 8, p. 70-80, jan./jul. 2000.

\section{SOBRE AS AUTORAS}

Lucíola Licínio de Castro Paixão Santos é doutora em educação pela Universidade de Londres. Professora titular da Universidade Federal de Minas Gerais (UFMG).

E-mail: luciolaufmg@yahoo.com.br

Regina Lúcia Cerqueira Dias é doutora em educação pela Universidade Federal de Minas Gerais (UFMG). Professora adjunta da Universidade Federal Fluminense (UFF).

E-mail: regcerdias@yahoo.com.br

Recebido em setembro de 2011 Aprovado em maio de 2012 


\section{LUCÍOLA LICÍNIO DE CASTRO PAIXÃO SANTOS E REGINA LÚCIA CERQUEIRA DIAS}

Trajetórias escolares e prática profissional de docentes das camadas populares

Este trabalho tem como objetivo investigar a influência da formação em nível superior nas mudanças ocorridas nas práticas pessoais e profissionais de um grupo de professoras oriundas das classes populares. Busca também identificar e analisar os fatores que contribuíram para que essas docentes obtivessem longevidade escolar, contribuindo 
ainda para uma reflexão sobre as atuais políticas de formação inicial de professores em nível superior. Quanto à prática docente, os relatos feitos pelo grupo de professoras revelaram mudanças importantes no habitus profissional das participantes da pesquisa. No entanto, o estudo também revelou algumas permanências em suas práticas que parecem indicar que alguns dos problemas vivenciados pelo grupo de docentes, advindos de suas formações familiar e escolar, ainda não foram superados por elas.

Palavras-chave: formação e prática docente; trajetórias escolares de docentes das camadas populares; habitus.

\section{School trajectories and professional practice of low-income teachers}

This study aims to investigate the influence of higher education on the changes in the personal and professional practices of a group of teachers coming from the lower classes. It also seeks to identify and analyze the factors that contributed to make these schoolteachers obtain school longevity. In addition it contributes to a reflection on the current policies of initial teacher education in higher education. As for teaching practice, the accounts by the group of teachers revealed important changes in theirprofessional "babitus". However, the study also revealed some constants in their practices that seem to indicate that some of the problems experienced by the group of teachers, arising from their family and school background, have not yet been overcome by them.

Keywords: teacher education and teaching practice; school trajectories from teachers from the lower classes; habitus.

\section{Trayectorias escolares y práctica profesional de docentes de los estratos populares}

Este trabajo objetiva investigar la influencia de la formación en nivel superior en los cambios ocurridos en las prácticas personales y profesionales de un grupo de profesoras originarias de estratos populares. Busca asimismo identificar y analizar los aspectos que contribuyeran para que esas docentes obtuviesen longevidad escolar viabilizando aún la reflexión acerca de las actuales politicas de formación inicial de profesores en nivel superior. Cuanto a la práctica docente, los relatos hechos por el grupo apuntan cambios importante en el habitus profesional de las participantes de la investigación. Sin embargo, el estudio también reveló algunas permanencias en sus prácticas que parecen indicar que algunos de los problemas vividos por ese grupo de docentes, advenidos de su formación familiar y escolar, todavía no fueron superados por ellas.

Palabras clave: formación y práctica docente; trayectorias escolares de docentes de los estratos populares; habitus. 